\title{
Palmitate Activates Insulin Signaling Pathway in Pancreatic Rat Islets
}

\author{
Maria Fernanda R. Graciano, PhD, Tatiane C.A. Nogueira, PhD, Carla R.O. Carvalho, MD, PhD, \\ Rui Curi, PhD, and Angelo R. Carpinelli, $M D, P h D$
}

\begin{abstract}
Objective: To investigate the action of palmitate on insulin receptor (IR) signaling pathway in rat pancreatic islets. The following proteins were studied: IR substrate-1 and -2 (IRS1 and IRS2), phosphatidylinositol 3-kinase, extracellular signal-regulated protein kinase-1 and -2 (ERK1/2), and signal transducer and activator of transcription 3 (STAT3).

Methods: Immunoblotting and immunoprecipitation assays were used to evaluate the phosphorylation states of IRS1 and IRS2 (tyrosine [Tyr]), ERK1/2 (threonine 202 [Thr202]/Tyr204), and STAT3 (serine [Ser727]). Results: The exposure of rat pancreatic islets to $0.1-\mathrm{mmol} / \mathrm{L}$ palmitate for up to 30 minutes produced a significant increase of Tyr phosphorylation in IRS2 but not in IRS1. The association of phosphatidylinositol 3-kinase with IRS2 was also upregulated by palmitate. Exposure to $5.6-\mathrm{mmol} / \mathrm{L}$ glucose caused a gradual decrease in ERK1/2 (Thr202/ Tyr204) and STAT3 (serine [Ser727]) phosphorylations after 30-minute incubation. The addition of palmitate $(0.1 \mathrm{mmol} / \mathrm{L})$, associated with 5.6-mmol/L glucose, abolished these latter effects of glucose after 15 -minute incubation.
\end{abstract}

Conclusions: Palmitate at physiological concentration associated with 5.6-mmol/L glucose activates IR signaling pathway in pancreatic $\beta$ cells.

Key Words: pancreatic islets, palmitate, insulin receptor signaling, IRS2, ERK1/2, STAT3

(Pancreas 2009;38: 578-584)

$S^{\text {hist }}$ hort-term exposure (1 hour) of pancreatic islets to free $S_{\text {fatty acids (FFAs) increases glucose-stimulated insulin se- }}$ cretion (GSIS) at high glucose concentration $(16.7 \mathrm{mmol} / \mathrm{L}) .{ }^{1-3}$ However, islet exposure to palmitate for a prolonged period ( 24 hours) shows low GSIS. ${ }^{4,5}$ The potentiation of GSIS is associated with inhibition of FFA oxidation, increased FFA esterification, and complex lipid synthesis by pancreatic $\beta$ cells. ${ }^{6}$ Pancreatic islets convert glucose into fatty acids, and a substantial amount of them is released to extracellular medium after 60-minute static incubation. ${ }^{7}$ The exported FFAs probably have an important paracrine function, amplifying GSIS. Despite this, the precise mechanisms by which FFA modulate insulin release by pancreatic $\beta$ cell are not fully understood yet.

From the Department of Physiology and Biophysics, Institute of Biomedical Sciences, University of São Paulo (USP), São Paulo, Brazil.

Received for publication August 19, 2008; accepted January 23, 2009.

Reprints: Maria Fernanda R. Graciano, PhD, Department of Physiology and Biophysics, Institute of Biomedical Sciences, University of São Paulo, Av. Prof. Lineu Prestes, 1524, São Paulo, Brazil (e-mail: mafe@ icb.usp.br).

This study was supported by grants from the Fundação de Amparo à Pesquisa do Estado de São Paulo, the Conselho Nacional de Desenvolvimento Cientifico e Tecnológico, and the Coordenação de Aperfeiçoamento de Pessoal de Nível Superior, Brazil. M.F.R.G. was supported by a PhD

fellowship from the Fundação de Amparo à Pesquisa do Estado de São Paulo.

Copyright (C) 2009 by Lippincott Williams \& Wilkins
Evidence exists that the autocrine action of insulin through insulin/insulin-like growth factor-1 receptor pathway is involved in maintaining $\beta$ cell mass and function. ${ }^{8-12}$ Insulin receptor substrate- 2 induces proliferation of pancreatic $\beta$ cells and protects them from apoptosis induced by chronically elevated glucose concentrations. ${ }^{13}$ Extracellular signal-regulated protein kinase-1 and -2 (ERK1/2) and signal transducer and activator of transcription 3 (STAT3) also play an important role for pancreatic $\beta$ cell survival and growth. In cultured islets, the pharmacological inhibition of ERK1/2 considerably reduced $\beta$ cell proliferation. ${ }^{14}$ Signal transducers and activators of transcription are cytoplasmic transcription factors activated by tyrosine (Tyr) phosphorylation and dimerization. ${ }^{15}$ Signal transducer and activator of transcription 3 is activated by a variety of growth factors, cytokines, and hormones and plays a critical role in proliferation and survival of pancreatic $\beta$ cells. ${ }^{16,17}$

Our previous results revealed an increase in insulin receptor (IR) protein content and its tyrosyl phosphorylation in isolated rat pancreatic islets exposed to $0.1-\mathrm{mmol} / \mathrm{L}$ palmitate and 5.6- $\mathrm{mmol} / \mathrm{L}$ glucose for 30 minutes. This effect was associated with protein palmitoylation but not to fatty acid oxidation. ${ }^{18}$ This was the first evidence for the action of fatty acids on insulin signaling pathway in pancreatic islets.

In the present report, we studied the short-term effect (up to 30 minutes) of palmitate on IR signaling pathway in rat pancreatic islets. Palmitate increased IR substrate-2 (IRS2) tyrosyl phosphorylation and its association with phosphatidylinositol 3-kinase (PI3K) and delayed ERK1/2 and STAT3 dephosphorylations observed in the presence of $5.6-\mathrm{mmol} / \mathrm{L}$ glucose.

\section{MATERIALS AND METHODS}

\section{Reagents}

Reagents for sodium dodecyl sulfate-polyacrylamide gel electrophoresis (SDS-PAGE) and immunoblotting were obtained from Bio-Rad (Richmond, Calif). Trizma, aprotinin, dithiothreitol, Triton X-100, glycerol, Tween 20, and sodium palmitate were obtained from Sigma (St Louis, Mo). Protein A Sepharose $6 \mathrm{MB}$ was obtained from Pharmacia (Uppsala, Sweden). The immunoblot enhanced chemiluminescence detection kit was from Amersham Pharmacia Biotech (Buckinghamshire, UK), and the nitrocellulose membrane $(0.45 \mu \mathrm{m})$ was from Bio-Rad (Hercules, Calif). Antiphosphotyrosine, anti-IRS1, and anti-IRS2 antibodies were from Santa Cruz Biotechnology (Santa Cruz, Calif); anti-p44/42 and anti-phosphop44/42 (Thr202/Tyr204) mitogen-activated protein kinases (MAPKs), anti-STAT3, and anti-phospho-STAT3 (serine 727 [Ser727]) antibodies were from Cell Signaling Technology (St Louis, Mo); anti-PI3K p85 was from Upstate Biotechnology (Lake Placid, NY); and anti- $\beta$-actin was from Zymed Laboratories (San Francisco, Calif). 
The anti-p44/42 and anti-phospho-p44/42 (Thr202/ Tyr204) MAPKs, anti-PI3K p85, and anti- $\beta$-actin antibodies were used at 1:1000 dilution. The antiphosphotyrosine, antiphospho-STAT3 (Ser727), and anti-STAT3 antibodies were used at dilutions of 1:400.

\section{Animals}

Female albino rats weighing 250 to $300 \mathrm{~g}$ were kept under standard lighting conditions (12-hour light-dark cycle) at a temperature of $23 \pm 1^{\circ} \mathrm{C}$, in groups of 5 , and were allowed access to standard rodent chow and water ad libitum. The study was approved by the Ethical Committee of the Institute of Biomedical Sciences, University of Sao Paulo.

\section{Isolation of Pancreatic Islets}

Islets were isolated by collagenase digestion of the pancreas after the method previously described by Lacy and Kostianovsky. ${ }^{19}$ Krebs-Henseleit buffer containing 115-mmol/L $\mathrm{NaCl}, 5-\mathrm{mmol} / \mathrm{L} \mathrm{KCl}, 24-\mathrm{mmol} / \mathrm{L} \mathrm{NaHCO}_{3}, 1-\mathrm{mmol} / \mathrm{L} \mathrm{CaCl}_{2}$, and $1-\mathrm{mmol} / \mathrm{L} \mathrm{MgCl}_{2}$ was used for pooling the islets.

\section{Immunoblotting}

Groups of 300 islets were incubated at $37^{\circ} \mathrm{C}$ in KrebsHenseleit buffer containing $5.6-\mathrm{mmol} / \mathrm{L}$ glucose equilibrated with a mixture of $95 \% \mathrm{O}_{2} / 5 \% \mathrm{CO}_{2}, \mathrm{pH} 7.4$, in the absence or presence of $0.1 \mathrm{mmol} / \mathrm{L}$ palmitate for 30 minutes. Palmitic acid was dissolved in ethanol before addition into the incubation medium to form an emulsified fatty acid solution. The final ethanol concentration in this fatty acid solution was $0.5 \%$. Preliminary experiments established that $0.5 \%$ ethanol has no effect on basal insulin release. ${ }^{3}$ At the end of the experiments, the islets were transferred to a tube containing $80 \mu \mathrm{L}$ of extraction buffer $(100-\mathrm{mmol} / \mathrm{L}$ Trizma, $1 \% \mathrm{SDS}, 100-\mathrm{mmol} / \mathrm{L}$ sodium pyrophosphate, $100-\mathrm{mmol} / \mathrm{L}$ sodium fluoride, $10-\mathrm{mmol} / \mathrm{L}$ EDTA, and $10-\mathrm{mmol} / \mathrm{L}$ sodium orthovanadate). They were homogenized using an ultrasonic processor (Sonics \& Materials, Newtown, Pa) and boiled for 10 minutes. The extracts were then centrifuged at $12,000 \mathrm{rpm}$ at $4^{\circ} \mathrm{C}$ for 20 minutes to remove insoluble material. Protein determination in the supernatants was performed by the Bradford dye method using the Bio-Rad reagent. $^{20}$

The whole extracts were treated with Laemmli sample buffer containing dithiothreitol and boiled for 5 minutes before loading onto $8 \%$ or $10 \%$ SDS-PAGE in a Bio-Rad miniature slab gel apparatus. Similar-sized aliquots (between 60 and $80 \mu \mathrm{g}$ ) were subjected to SDS-PAGE. The electrotransfer of proteins from the gel to the nitrocellulose membrane was performed for 1.5 hours at $120 \mathrm{~V}$ (direct current) in a Bio-Rad miniature transfer apparatus. Non-specific protein binding to the nitrocellulose membrane was reduced by preincubation for 2 hours at $22^{\circ} \mathrm{C}$ in blocking buffer $(5 \%$ nonfat dry milk, $10-\mathrm{mmol} / \mathrm{L}$ Trizma, $150-\mathrm{mmol} / \mathrm{L} \mathrm{NaCl}$, and $0.02 \%$ Tween 20 ). The nitrocellulose membranes were incubated overnight at $4^{\circ} \mathrm{C}$ with antibodies diluted in blocking buffer with $3 \%$ nonfat dry milk and then washed for 30 minutes. The membranes were subsequently incubated with peroxidase-conjugated secondary antibody for 1 hour and processed for enhanced chemiluminescence to visualize the immunoreactive bands. Band intensities were quantified by optical densitometry (Scion Image-Release Beta $3 \mathrm{~b}$; National Institutes of Health, Bethesda, Md) of the developed autoradiographs.

\section{Immunoprecipitation Assay}

For immunoprecipitation followed by immunoblot analysis, groups of 500 pancreatic islets were exposed to the exper- imental conditions described previously. Equal amounts of the supernatant of the whole extracts were used in immunoprecipitation experiments. The composition of the extraction buffer was $100-\mathrm{mmol} / \mathrm{L}$ Trizma, $100-\mathrm{mmol} / \mathrm{L}$ sodium pyrophosphate, 100-mmol/L sodium fluoride, 10-mmol/L EDTA, 10-mmol/L sodium orthovanadate, $2-\mathrm{mmol} / \mathrm{L}$ phenylmethylsulfonyl fluoride (PMSF), $0.01-\mathrm{mg} / \mathrm{mL}$ aprotinin and $1 \%$ Triton $\mathrm{X}-100$. The samples were incubated with anti-IRS1 or IRS2 antibodies at $4^{\circ} \mathrm{C}$ overnight, followed by addition of Protein A Sepharose $6 \mathrm{MB}$ for 2 hours. The pellets were repeatedly washed in buffer, resuspended in $50 \mu \mathrm{L}$ of Laemmli sample buffer and boiled for 5 minutes before loading onto the gel.

\section{Caspase 3 Activity}

The J774 murine macrophage cell line was used as a positive control for caspase activity assay in incubation with $1-\mu \mathrm{mol} / \mathrm{L}$ staurosporine, a proapoptotic agent, for 6 hours. J774 cells were grown in RPMI-1640 medium containing $10 \%$ fetal calf serum. This medium was supplemented with glutamine

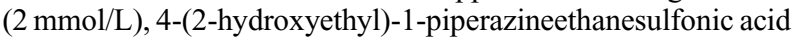
(HEPES; $20 \mathrm{mmol} / \mathrm{L})$, streptomycin $(10,000 \mu \mathrm{g} / \mathrm{mL})$, penicillin $(10,000 \mathrm{UI} / \mathrm{mL})$, and sodium bicarbonate $(24 \mathrm{mmol} / \mathrm{L})$. The cells were kept in a humidified atmosphere containing $5 \%$ $\mathrm{CO}_{2}$ at $37{ }^{\circ} \mathrm{C}$.

The $\mathrm{J} 774$ cells were centrifuged at $1000 \mathrm{~g}$ for 15 minutes at $4{ }^{\circ} \mathrm{C}$. The pellet of cells or the samples with 200 islets were resuspended in $200 \mu \mathrm{L}$ of lyse buffer containing $10 \%$ sucrose, $0.1 \%$ 3-[(3-cholamidopropyl)-dimethylammonio]-1propanesulfonate, 100-mmol/L HEPES, pH 7.4, 10-mg/mL leupeptin, $10-\mathrm{mg} / \mathrm{mL}$ aprotinin, 200-mmol/L PMSF, and 10$\mathrm{mmol} / \mathrm{L}$ dithiothreitol. The samples were incubated for 30 minutes at $4^{\circ} \mathrm{C}$ and centrifuged at $12,000 \mathrm{~g}$ for 30 minutes at $4^{\circ} \mathrm{C}$. The supernatant was collected, and protein was determined by Bradford. ${ }^{20}$ Caspase protease activity was determined by incubating the lysate $(20 \mu \mathrm{g}$ of total protein) with $50 \mu \mathrm{mol} / \mathrm{L}$ of the fluorogenic caspase 3 substrate AC-DEVD-AMC (ac-AspGlu-Val-Asp-AMC) in the buffer $(10 \%$ sucrose, $100-\mathrm{mmol} / \mathrm{L}$ HEPES, pH 7.4, 10-mg/mL leupeptin, $10-\mathrm{mg} / \mathrm{mL}$ aprotinin, 200-mmol/L PMSF, and 10-mmol/L dithiothreitol). The caspase activity was assessed by measuring the fluorescence of Asp7-amino-4-trifluoromethyl coumarin released for 30 minutes at 5-minute intervals by using a spectrofluorometer (Spectra MAX Gemini XS; Molecular Devices, Sunnyvale, Calif). ${ }^{21}$

\section{Statistical Analysis}

Results are presented as means (SEM). Comparisons between groups were performed using analysis of variance. Significant differences were assessed by using the Tukey-Kramer test (InStat; GraphPad Software, Inc, San Diego, Calif). Student unpaired $t$ test was used for a comparison between only 2 groups. The level of significance was set to $P<0.05$.

\section{RESULTS}

\section{Insulin Receptor Substrate-2 Phosphorylation and Association With PI3K Was Upregulated by Palmitate}

Palmitate induced a significant increase in Tyr phosphorylation of IRS2 but not of IRS1 (Figs. 1A, B). Phosphatidylinositol 3-kinase-IRS2 association was increased by the fatty acid, but the PI3K/IRS1 association remained unchanged (Figs. 1C, D). The increment of tyrosyl phosphorylation was 

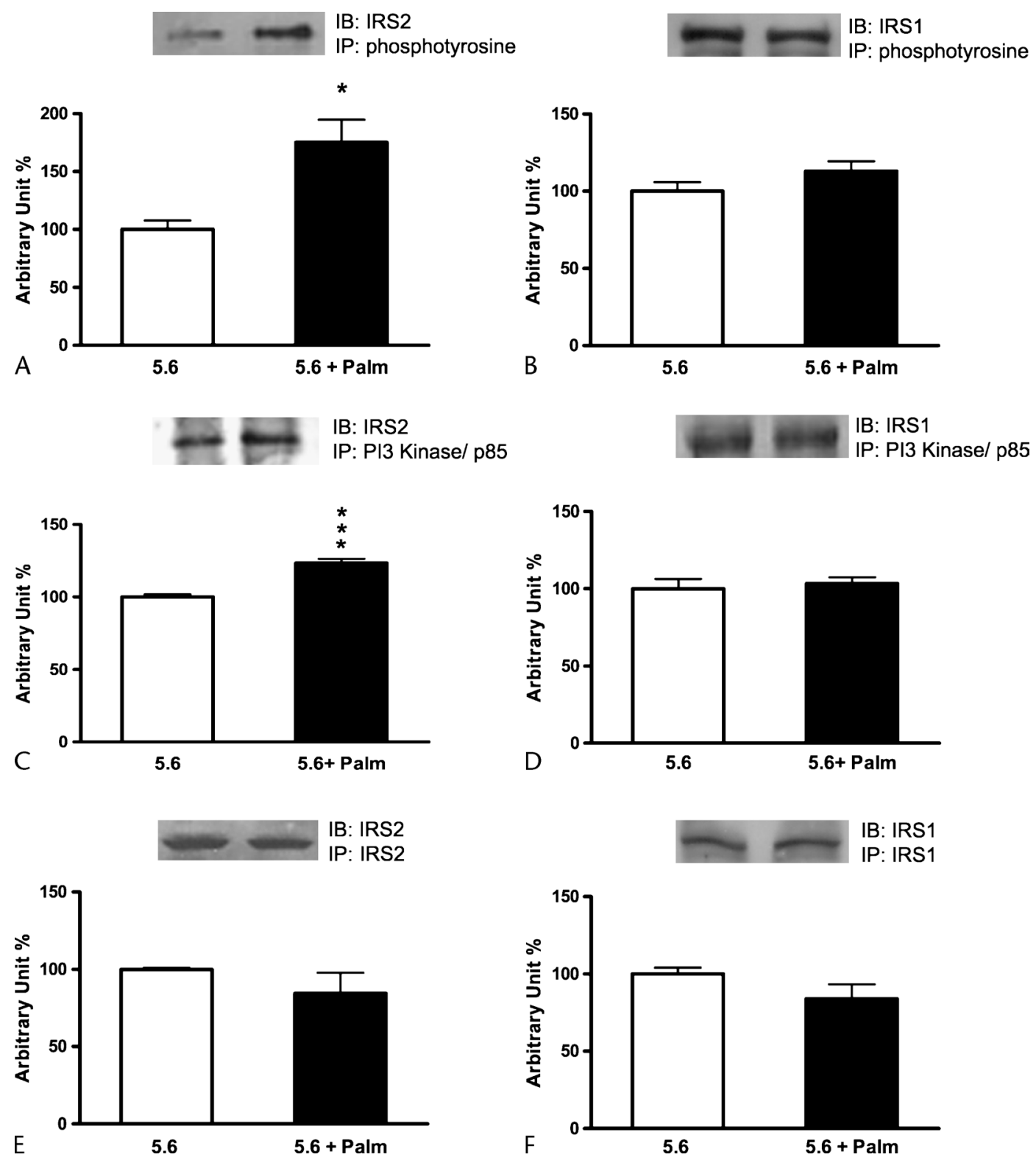

FIGURE 1. Effect of palmitate on Tyr phosphorylation and association of IRS1/2 with PI3K. Palmitate induced Tyr phosphorylation of IRS2 (A) but not of IRS1 (B) and increased the association of the p85 subunit of PI3K to IRS2 (C) with no alteration of its association with IRS1 (D) in isolated rat pancreatic islets. The contents of IRS2 (E) and IRS1 (F) were not altered by the fatty acid. Groups of 500 islets were incubated with 5.6-mmol/L glucose (white bars) or with $5.6-\mathrm{mmol} / \mathrm{L}$ glucose and $0.1-\mathrm{mmol} / \mathrm{L}$ palmitate (black bars) for 30 minutes. The islets were homogenized in extraction buffer, and after centrifugation, aliquots with the same amount of proteins were immunoprecipitated (IP) with anti-IRS2 or anti-IRS1 and immunoblotted (IB) with antiphosphotyrosine, PI3K/p85, IRS1, or IRS2 antibodies. The bars represent the relative phosphorylation or protein expression as determined by optical densitometry and are presented as mean (SEM) of 4 experiments. $* P<0.05$ and $* * * P<0.001$ as compared with 5.6-mmol/L glucose.

not caused by a raise in the amount of IRS2, which remained constant during the experiments (Figs. 1E, F).

\section{Palmitate Delayed the Decrease in ERK1/2 and STAT3 Phosphorylations Observed in Incubation With 5.6- $\mathrm{mmol} / \mathrm{L}$ Glucose}

The pancreatic islets incubated in the presence of 5.6$\mathrm{mmol} / \mathrm{L}$ glucose showed ERK $1 / 2$ dephosphorylation after 15 minutes. The addition of palmitate into the medium induced a delay of ERK dephosphorylation, which was detected only after 30 minutes of incubation (Figs. 2A, B). As observed for ERK1/2 phosphorylation, palmitate also induced a delay in the dephosphorylation of STAT3 (Ser727) during 30 minutes (Figs. 2C, D). The phosphorylation levels of ERK1/2 and STAT3 after 30-minute incubation did not differ between the 2 conditions (data not shown). However, distinct of that detected in the ERK proteins levels, which remained unchanged (Figs. 2A, B), there was a decreased level of STAT3 protein along the time course incubation with glucose or in association with the fatty acid (Figs. 2E, F). 

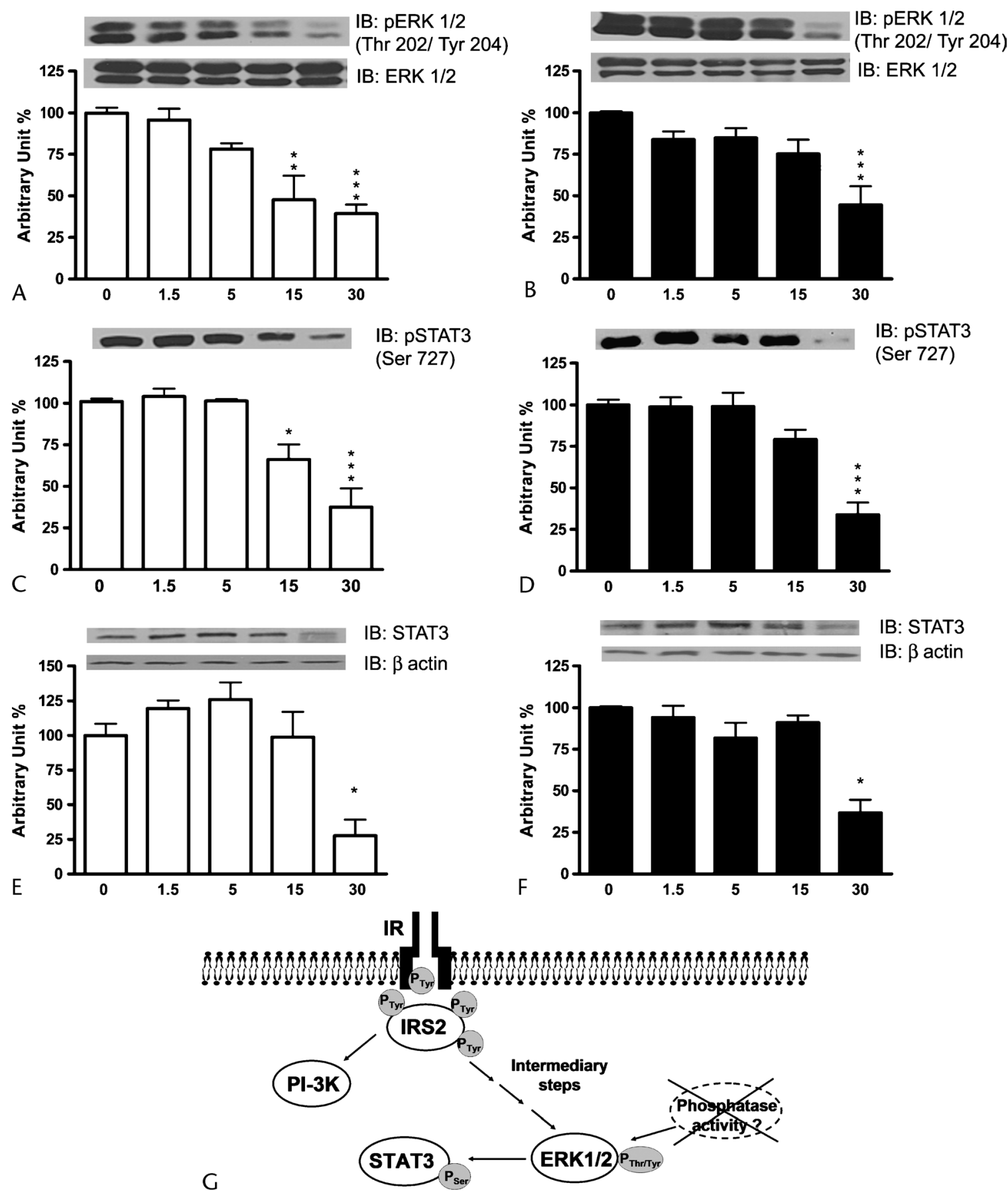

FIGURE 2. Time course effect of palmitate and 5.6-mmol/L glucose on ERK $1 / 2$ and STAT3 phosphorylations. The bars express the time course of phosphorylation of ERK1/2 (Thr202/Tyr204; A and B) and STAT3 (Ser727; C and D) and the content of STAT3 (E and F) during 0 - to 30-minute incubation of isolated rat pancreatic islets. Groups of 300 islets were incubated with $5.6-\mathrm{mmol} / \mathrm{L}$ glucose (white bars) or with $5.6-\mathrm{mmol} / \mathrm{L}$ glucose and $0.1-\mathrm{mmol} / \mathrm{L}$ palmitate (black bars) for different periods. The bars represent the relative phosphorylation or protein expression as determined by optical densitometry and are presented as mean (SEM) of 3 experiments. ${ }^{*} P<0.05, * * P<0.01$, and $* * * P<0.001$ compared with 0 -minute time, the initial incubation period. $G$, Insulin signaling pathway activated by palmitate in pancreatic islets: the increase in IR Tyr phosphorylation by palmitate as previously demonstrated ${ }^{18}$ induced an increase in Tyr phosphorylation of IRS2, which is associated with PI3K activation. Insulin receptor substrate-2 tyrosyl phosphorylation induced by palmitate also activated the ERK/STAT3 pathway. Potentialization of ERK activity could also be a result of down-regulation of phosphatase activity, improving STAT3 serine phosphorylation. 

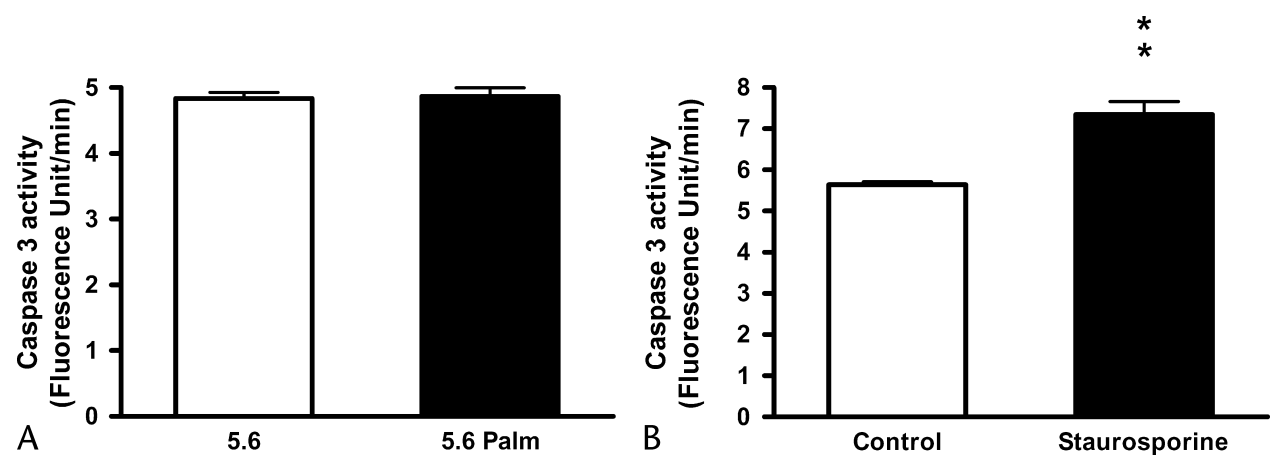

FIGURE 3. Effects of $0.1-\mathrm{mmol} / \mathrm{L}$ palmitic acid and $1-\mathrm{mmol} / \mathrm{L}$ staurosporine on caspase 3 activity. $\mathrm{A}$, The activity of caspase 3 in pancreatic islets after treatment for 30 minutes with $5.6-\mathrm{mmol} / \mathrm{L}$ glucose $(5.6)$ and addition of $0.1-\mathrm{mmol} / \mathrm{L}$ palmitic acid (5.6 Palm) is shown.

B, For positive control, caspase 3 activity was measured in 1774 murine macrophage cell line incubated with 1 - $\mu$ mol/L staurosporine for 6 hours. Protease activity was determined by incubating concomitantly the lysates of islets and J774 cells ( $20 \mu \mathrm{g}$ of total protein) with $50-\mu \mathrm{mol} / \mathrm{L}$ of the fluorogenic substrate AC-DEVD-AMC in the lyse buffer. Caspase activity was assessed by measuring fluorescent Asp-7-amino-4-trifluoromethyl coumarin released for 30 minutes at 5-minute intervals by using a spectrofluorometer. The values are presented as mean (SEM) of 3 experiments. ${ }^{* * P}<0.01$ for comparison between the treatment with staurosporine and control.

\section{Palmitate Did Not Change Caspase 3 Activity}

The activity of caspase 3, an early apoptotic event, was not raised by exposure of pancreatic islets to palmitic acid for 30 minutes (Fig. 3).

\section{DISCUSSION}

Palmitate induced a significant increase in IRS2 Tyr phosphorylation (Fig. 1A) that was not caused by the raise in the amount of this protein (Fig. 1E). This fact suggests that palmitate at physiological concentration range, and in the presence of $5.6-\mathrm{mmol} / \mathrm{L}$ glucose, regulates IR-activated pathways in pancreatic islets via IRS2.

Insulin receptor substrate- 2 phosphorylation activates at least two $\beta$-cell signaling pathways: the PI3K and the MAPK. $^{22,23}$ Palmitate induced IRS2 phosphorylation (Fig. 1A), its association with PI3K (Fig. 1C), and delayed ERK1/2 (Figs. 2A, B) and STAT3 (Figs. 2C, D) dephosphorylations in the presence of 5.6-mmol/L glucose (Fig. 2G). These findings support the proposition that short-time exposure to palmitic acid raises pancreatic $\beta$ cell survival. Simon et $\mathrm{al}^{24}$ have shown that short-period exposure to fatty acids is not enough to induce cytotoxicity in pancreatic $\beta$ cells because survival pathways are activated. Therefore, palmitate is an important modulator of pancreatic islet function.

In the presence of 5.6- $\mathrm{mmol} / \mathrm{L}$ glucose, glucose oxidation is decreased in the presence of palmitate, ${ }^{3}$ probably because of a reduction in the flux of substrates through the tricarboxylic acid cycle. Under this condition, there is an increase in palmitate oxidation and also in its incorporation into lipid fractions, mainly phospholipids and triacylglycerols in pancreatic islets. ${ }^{3}$

Insulin receptor substrate-2 tyrosyl phosphorylation activates MAPK/STAT3 pathway through association with growth factor receptor-bound protein-2 coupled to the mammalian Son of Sevenless, which activates Ras. This latter protein activates Ser/Thr protein kinase Raf-1 that phosphorylates MAP/ERK kinase, leading to ERK1/2 phosphorylation. $^{25}$ Extracellular signal-regulated protein kinase, a well-studied MAPK, is stimulated by growth factors, ${ }^{26,27}$ and a prolonged activation of ERK1/2 and PI3K signaling pathways is important in committing $\beta$ cell to mitogenesis. ${ }^{22}$

As described by Costes et al, ${ }^{28}$ the treatment of islets with high glucose concentration $(16.7 \mathrm{mmol} / \mathrm{L})$ induced a transient phosphorylation of ERK1/2 and rapid dephosphorylation that could be associated with the isolation procedure. The addition of palmitate delayed ERK dephosphorylation observed in the presence of 5.6-mmol/L glucose (Figs. 2A, B). Therefore, the addition of a physiological concentration of fatty acid in association with basal glucose concentration could attenuate this spontaneous dephosphorylation. One downstream pathway of ERK1/2 activation is the serine phosphorylation of STAT3, which is activated by dual phosphorylation (Tyr705 and Ser727). Tyrosine 705 phosphorylation is required for cytokine-induced STAT3 dimerization, nuclear translocation, and DNA binding. However, full transcriptional activity of the homodimer is manifested only when Ser727 in the transactivation domain is also phosphorylated. ${ }^{29}$ Extracellular signal-regulated protein kinases modulate the transcriptional activity of STAT3 by phosphorylation at Ser727. ${ }^{30-32}$ After phosphorylation, STAT3 migrates to the nucleus to exert its effects on a transcriptional regulation level. In this scenario, one hypothesis to be considered is that the detected decrease in STAT3 protein level after 30 -minute incubation in the presence of $5.6-\mathrm{mmol} / \mathrm{L}$ glucose and $0.1-\mathrm{mmol} / \mathrm{L}$ palmitate (Figs. $2 \mathrm{E}, \mathrm{F}$ ) could be caused by the degradation of this transcription factor.

On the other hand, the decreased phosphorylation of ERK (Figs. 2A, B), with no modification of ERK protein level, may be associated with the regulation of the phosphorylation state of the molecule through phosphatase activity. Serine-phosphatases, tyrosine-phosphatases, or dual-specificity phosphatases can regulate MAPK in vivo. ${ }^{33,34}$ The delayed ERK dephosphorylation by the fatty acid in pancreatic islets (Fig. 2B) may represent a down-regulation of these phosphatases, producing a potentialization of this pathway.

The delay of ERK dephosphorylation induced by palmitate might enhance STAT3 serine phosphorylation (Figs. 2C, D), controlling its transcriptional activity. Signal transducer and activator of transcription 3 upregulates the expression of several genes involved in cell cycle progression ${ }^{35,36}$ such as cyclin $D, c-m y c$, and/or pim-1 and of anti-apoptotic genes such as Bcl-2 and $B c l-X L{ }^{37}$ The expression of a constitutively activated form of STAT3 in pancreatic $\beta$ cells is associated with normal islet morphology and glucose-induced early-phase insulin secretion. ${ }^{16,38}$ These observations indicate the importance of this transcriptional factor for maintenance of pancreatic $\beta$ cell mass and function. 
Long-chain saturated fatty acid molecules such as palmitate cause apoptosis of pancreatic islets, producing activation of caspase 3 after 24 hours. ${ }^{39}$ However, under physiological and short time exposure, palmitate did not change caspase 3 activity (Fig. 3A). Palmitic acid is one of the most prevalent fatty acids in plasma and might activate important signaling mechanisms in pancreatic islets for maintenance of $\beta$ cell mass.

In conclusion, we reported herein that palmitate exposure for a short period increased IRS2 Tyr phosphorylation and PI3K activity and caused a delay of ERK and STAT3 dephosphorylation. Thus, palmitate at physiological concentration range may play an important role to preserve the pancreatic $\beta$ cell machinery and function.

\section{ACKNOWLEDGMENTS}

The authors are grateful to Marlene Santos Rocha and Thais Martins de Lima for the excellent technical assistance. Thanks are due to Mauro Leonelli and Fernando Abdulkader for critically reviewing the manuscript.

\section{REFERENCES}

1. Crespin SR, Greenough WB, Steinberg D. Stimulation of insulin secretion by long-chain free fatty acids. A direct pancreatic effect. J Clin Invest. 1973;52:1979-1984.

2. Warnotte C, Gilon P, Nenquin M, et al. Mechanisms of the stimulation of insulin release by saturated fatty acids. A study of palmitate effects in mouse beta-cells. Diabetes. 1994;43:703-711.

3. Carpinelli AR, Picinato MC, Stevanato E, et al. Insulin secretion induced by palmitate - a process fully dependent on glucose concentration. Diabetes Metab. 2002;28:3S37-S44; discussion 3S108-12.

4. Wang Y, Wang PY, Takashi K. Chronic effects of different non-esterified fatty acids on pancreatic islets of rats. Endocrine. 2006;29:169-173.

5. Zhou YP, Grill VE. Long-term exposure of rat pancreatic islets to fatty acids inhibits glucose-induced insulin secretion and biosynthesis through a glucose fatty acid cycle. J Clin Invest. 1994;93:870-876.

6. Prentki M, Corkey BE. Are the beta-cell signaling molecules malonyl-CoA and cystolic long-chain acyl-CoA implicated in multiple tissue defects of obesity and NIDDM? Diabetes. 1996;45:273-283.

7. Martins EF, Miyasaka CK, Newsholme P, et al. Changes of fatty acid composition in incubated rat pancreatic islets. Diabetes Metab. 2004;30:21-27.

8. Aspinwall CA, Qian WJ, Roper MG, et al. Roles of insulin receptor substrate-1, phosphatidylinositol 3-kinase, and release of intracellular $\mathrm{Ca} 2+$ stores in insulin-stimulated insulin secretion in beta-cells. J Biol Chem. 2000;275:22331-22338.

9. Khan FA, Goforth PB, Zhang M, et al. Insulin activates ATP-sensitive $\mathrm{K}(+)$ channels in pancreatic beta-cells through a phosphatidylinositol 3-kinase-dependent pathway. Diabetes. 2001;50:2192-2198.

10. Withers DJ, Burks DJ, Towery HH, et al. IRS-2 coordinates Igf-1 receptor-mediated beta-cell development and peripheral insulin signalling. Nat Genet. 1999;23:32-40.

11. Kubota N, Tobe K, Terauchi Y, et al. Disruption of insulin receptor substrate 2 causes type 2 diabetes because of liver insulin resistance and lack of compensatory beta-cell hyperplasia. Diabetes. 2000;49: 1880-1889.

12. Leibiger IB, Leibiger B, Moede T, et al. Exocytosis of insulin promotes insulin gene transcription via the insulin receptor/PI-3 kinase/p70 s6 kinase and CaM kinase pathways. Mol Cell. 1998;1:933-938.
13. Mohanty S, Spinas GA, Maedler K, et al. Overexpression of IRS2 in isolated pancreatic islets causes proliferation and protects human beta-cells from hyperglycemia-induced apoptosis. Exp Cell Res. 2005;303:68-78.

14. Blandino-Rosano M, Perez-Arana G, Mellado-Gil JM, et al. Anti-proliferative effect of pro-inflammatory cytokines in cultured beta cells is associated with extracellular signal-regulated kinase $1 / 2$ pathway inhibition: protective role of glucagon-like peptide-1. J Mol Endocrinol. 2008;41:35-44.

15. Darnell JE Jr, Kerr IM, Stark GR. Jak-STAT pathways and transcriptional activation in response to IFNs and other extracellular signaling proteins. Science. 1994;264:1415-1421.

16. Tsukiyama S, Matsushita M, Matsumoto S, et al. Transduction of exogenous constitutively activated Stat 3 into dispersed islets induces proliferation of rat pancreatic beta-cells. Tissue Eng. 2006;12: 131-140.

17. Tanabe K, Okuya S, Tanizawa Y, et al. Leptin induces proliferation of pancreatic beta cell line MIN6 through activation of mitogen-activated protein kinase. Biochem Biophys Res Commun. 1997;241:765-768.

18. Haber EP, Hirabara SM, Gomes AD, et al. Palmitate modulates the early steps of insulin signalling pathway in pancreatic islets. FEBS Lett. 2003;544:185-188.

19. Lacy PE, Kostianovsky M. Method for the isolation of intact islets of Langerhans from the rat pancreas. Diabetes. 1967;16:35-39.

20. Bradford MM. A rapid and sensitive method for the quantitation of microgram quantities of protein utilizing the principle of protein-dye binding. Anal Biochem. 1976;72:248-254.

21. Andersson M, Sjostrand J, Petersen A, et al. Caspase and proteasome activity during staurosporin-induced apoptosis in lens epithelial cells. Invest Ophthalmol Vis Sci. 2000;41:2623-2632.

22. Lingohr MK, Dickson LM, McCuaig JF, et al. Activation of IRS-2-mediated signal transduction by IGF-1, but not TGF-alpha or EGF, augments pancreatic beta-cell proliferation. Diabetes. 2002;51: 966-976.

23. Rhodes CJ, White MF. Molecular insights into insulin action and secretion. Eur J Clin Invest. 2002;32(suppl 3):3-13.

24. Simon MN, Azevedo-Martins AK, Amanso AM, et al. Persistent activation of Akt or ERK prevents the toxicity induced by saturated and polyunsaturated fatty acids in RINm5F beta-cells. Toxicol In Vitro. 2008;22:1018-1024.

25. Pearson LL, Castle BE, Kehry MR. CD40-mediated signaling in monocytic cells: up-regulation of tumor necrosis factor receptor-associated factor mRNAs and activation of mitogen-activated protein kinase signaling pathways. Int Immunol. 2001;13:273-283.

26. Brunet A, Roux D, Lenormand P, et al. Nuclear translocation of p42/p44 mitogen-activated protein kinase is required for growth factor-induced gene expression and cell cycle entry. EMBO J. 1999; 18:664-674.

27. Cobb MH, Goldsmith EJ. How MAP kinases are regulated. J Biol Chem. 1995;270:14843-14846.

28. Costes S, Broca C, Bertrand G, et al. ERK1/2 control phosphorylation and protein level of cAMP-responsive element-binding protein: a key role in glucose-mediated pancreatic beta-cell survival. Diabetes. 2006;55:2220-2230.

29. Wen Z, Zhong Z, Darnell JE Jr. Maximal activation of transcription by Stat 1 and Stat 3 requires both tyrosine and serine phosphorylation. Cell. 1995;82:241-250.

30. Chung J, Uchida E, Grammer TC, et al. STAT3 serine phosphorylation by ERK-dependent and -independent pathways negatively modulates its tyrosine phosphorylation. Mol Cell Biol. 1997;17:6508-6516.

31. Lim CP, Cao X. Serine phosphorylation and negative regulation of Stat3 by JNK. J Biol Chem. 1999;274:31055-31061. 
32. Lo RK, Cheung H, Wong YH. Constitutively active Galpha16 stimulates STAT3 via a c-Src/JAK- and ERK-dependent mechanism. J Biol Chem. 2003;278:52154-52165.

33. Keyse SM. Protein phosphatases and the regulation of mitogen-activated protein kinase signalling. Curr Opin Cell Biol. 2000;12:186-192.

34. Saxena M, Mustelin T. Extracellular signals and scores of phosphatases: all roads lead to MAP kinase. Semin Immunol. 2000;12:387-396.

35. Fukada T, Ohtani T, Yoshida Y, et al. STAT3 orchestrates contradictory signals in cytokine-induced $\mathrm{G} 1$ to $\mathrm{S}$ cell-cycle transition. EMBO J. 1998;17:6670-6677.

36. Shirogane T, Fukada T, Muller JM, et al. Synergistic roles for Pim-1 and
c-Myc in STAT3-mediated cell cycle progression and antiapoptosis. Immunity. 1999;11:709-719.

37. Catlett-Falcone R, Landowski TH, Oshiro MM, et al. Constitutive activation of Stat 3 signaling confers resistance to apoptosis in human U266 myeloma cells. Immunity. 1999;10:105-115.

38. Gorogawa S, Fujitani Y, Kaneto H, et al. Insulin secretory defects and impaired islet architecture in pancreatic beta-cell-specific STAT3 knockout mice. Biochem Biophys Res Commun. 2004;319:1159-1170.

39. Abaraviciene SM, Lundquist I, Salehi A. Rosiglitazone counteracts palmitate-induced beta-cell dysfunction by suppression of MAP kinase, inducible nitric oxide synthase and caspase 3 activities. Cell Mol Life Sci. 2008;65:2256-2265. 